\title{
Developing Safety Management Systems for Track Workers Using Smart Phone GPS
}

\author{
Jin-Hee $\mathrm{Ku}^{1}$ and Duk-Kyu Park ${ }^{2 *}$ \\ ${ }^{l}$ Dept of Liberal Education and ${ }^{2}$ Dept of Information Communication Engineering \\ Mokwon University, Doan-Dong, Seo-gu, Daejeon, 302-729, Korea \\ jhku@mokwon.ac.kr,parkdk@mokwon.ac.kr
}

\begin{abstract}
When performing railroad maintenance work on the railroad, the train watchmen give information of train access to railroad maintenance workers by radio through hand-signals and/or a radio. These existing methods have the possibility of making errors of information delivery due to weather situation, work structures or obstacles, and because railroad maintenance workers usually concentrate on their work, many chances are that they would not recognize the access of trains. In order to reduce the risk of railway traffic accidents of death and injury for track workers, this paper has developed a system that notifies track workers of train approaching information by combining the GPS location providing function of the smart phone and a notification system. The developed system does not need the construction of an independent wireless communication system, and is designed to notify track workers of train approaching information by using a simple Bluetooth module and safety jackets. Also, the system establishes a simple communication possible by using the bluetooth equipped in the smart phone between the alarm system and smart phones. If the proposed system is in use, it is expected that it can contribute to the prevention and reduction of railroad accidents of railroad maintenance workers by preventing accidents of railroad maintenance workers and securing their safety.
\end{abstract}

Keywords: Smart Phone, Accident of Trackside, GPS (global positioning system), Safety Alarm Equipment

\section{Introduction}

For the sake of safe train driving, it is essential to check the states of railway tracks and maintain and repair signal control equipment located trackside. As most of this maintenance work is done by track workers, it is necessary to secure their safety. Railway accidents of death and injury often occur in which trains run against track workers due to sensory disorder in which track workers do not recognize approaching trains as they carry out monotonous jobs for long when they are absorbed in track work [1].

This paper has developed a safety management system for track workers that does not need independent construction of a wireless system, using the explosive spread of smart phones and their merits in providing location information. The developed system is designed to prevent accidents of death and injury by notifying track workers of information of train approaching with its management of location information of trains and track workers. It is also designed to provide information signals for track workers by means of various pieces of

${ }^{*}$ Corresponding Author 
safety equipment including vibration, sounds, LED, etc., in order to prevent sensory disorder in track workers. Such pieces of safety equipment are installed in safety jackets provided for track workers. The safety equipment plays the role of notifying track workers of train approaching by embodying a simple communication module by means of Bluetooth to allow it to be engaged in wireless communication with the built-in Bluetooth of smart phones.

The proposed system has not been applied to railway, but its effectiveness was proved by the development of a test product based on the design. The second chapter of this paper takes a look at the conditions of accidents of death and injury among track workers and of safety equipment for reducing the occurrence of such accidents, and the third chapter accounts for the structure of the safety management system for track workers using the smart phone GPS. Also, Chapter 4 presents the developed system and the results of a simulation, and then, finally, Chapter 5 concludes the paper.

\section{Related Works}

\subsection{Conditions of Accidents of Death and Injury in Among Track Workers}

Currently domestic railway accidents of death and injury are divided into railway traffic accidents of death and injury and railway safety accidents of death and injury. A railway traffic accident of death and injury refers to one occurring directly to passengers, the public, duties etc. by railway trains, while a railway safety accident one occurring by railway facilities without train driving or direct contact with vehicles [2].

Table 1. Railway Casualty Accident Statistics

\begin{tabular}{c|c|c|c|c|c}
\hline & $\mathbf{2 0 0 8}$ & $\mathbf{2 0 0 9}$ & $\mathbf{2 0 1 0}$ & $\mathbf{2 0 1 1}$ & $\mathbf{2 0 1 2}$ \\
\hline \hline $\begin{array}{c}\text { Railway } \\
\text { Accidents }\end{array}$ & 7 & 3 & 4 & 2 & 6 \\
\hline $\begin{array}{c}\text { Railroad Crossing } \\
\text { Accidents }\end{array}$ & 24 & 20 & 17 & 14 & 10 \\
\hline $\begin{array}{c}\text { Accidents of Death and } \\
\text { Injury }\end{array}$ & 376 & 357 & 294 & 257 & 231 \\
\hline
\end{tabular}

The statistics of railway accidents of death and injury in table 1 shows the numbers of accidents and casualties as aggregated yearly with respect to accident types and causes. According to this table, a total of 22 railway accidents occurred between 2008 2012, and hence this means about 4.4 yearly accidents in average. Also, a total of 85 railroad crossing accidents occurred, which means yearly average reduction by about $20.3 \%$, while there were a total of 1,515 accidents of death and injury, which means yearly average reduction by about $11.3 \%$. By analysis, the causes of reduction include continuous improvement of facilities like double tracking, railway electrification, automation, etc., overall betterment of railway environments including introduction of state-of-the-art vehicles, modernization of maintenance equipment, etc., and publicity of safety via reinforcement of education and training of accident prevention for railway employees as well as electric message signs. Also, by analysis, the causes include extension of safety facilities like installation of screen doors and trackside safety fences, and enhancement of overall railway safety management including systematic establishment and improvement of railway safety systems and periodical administration of safety monitoring of facilities [3].

However, since railway traffic accidents of death and injury account for about $87 \%$ of the whole accidents of death and injury, which occupy more than $90 \%$ of the equal death index of 
the whole railway accidents [4], need is raised to work on many measures for preventing and reducing railway traffic accidents of death and injury.

\subsection{Conditions of Safety Equipment for Reducing Accidents of Death and Injury for Track Workers}

Consideration of the statistics about railway accidents of death and injury for the recent 5 years reveals that the number and damages of railway accidents of death and injury tend to be reduced every year, but job accidents of death an injury related to track workers still remain unreduced.

One should simultaneously consider safe train driving and worker safety because trackside maintaining jobs are carried out in consideration of train driving due to their characteristics [5].

Thus, first of all, for the purpose of the reduction of accidents of death and injury among track workers, research should be driven to secure safety for track workers from risk factors including extension of the range of train monitoring, and minimization of evacuation time from trains for workers.

Recently, safety equipment has been proposed that can notify train approaching information by means of wireless signals between trains and track workers in order to prevent railway accidents of death and injury [6], and a system for preventing accidents of death and injury among track workers by executing location tracking based on the RFID is under development [7]. However, such systems are disadvantageous in that an independent wireless communication system should be constructed, and the construction of the system costs much money.

In the current situation, almost everyone uses a cellular phone as a communication device as mobile communication has been spread rapidly. In particular, most cell phone users use smart phones in that smart phone users account for more than $60 \%$ of cell phone users in Korea due to recent rapid increase in the number of smart phone users. Smart phone use has merits in that one can be provided with various services using diverse applications. Also, as smart phones have the GPS (Global Positioning System) in them, we can share each other's location information, and use location-based applications, by which we can be provided with various information including locations among groups with the same interest [8].

Using the explosive spread of smart phones and their merits in providing location information, this paper has developed a safety management system for track workers without any independent wireless system construction. The safety management system for track workers using smart phones proposed in this paper is expected to contribute itself to the reduction of accidents of death and injury among track workers by preventing railway accidents of death and injury securing their safety at a low price without any construction of new wireless communication system.

\section{Design of the Safety Management System for Track Workers Using the Smart Phone GPS}

\subsection{Development Environment}

This system monitors train approaching information in real time for track workers by managing location information of both driven trains and track workers at the same time, and minimizes evacuation time from trains for track workers by transmitting signals to track worker's safety jackets via various types of safety equipment in case of danger. 
The development environment of this system is as follow.

Table 2. Development Environment

\begin{tabular}{c|c|l}
\hline System & Program Tool & \multicolumn{1}{c}{ Description } \\
\hline \hline \multirow{4}{*}{ S/W } & OS & $\begin{array}{l}\text { ・ Windows7 } \\
\bullet\end{array}$ \\
\cline { 2 - 3 } & Database & $\bullet$ Postgres8.4 \\
\cline { 2 - 3 } & Web Server & $\bullet$ Apache Tomcat5.5 \\
\cline { 2 - 3 } & Development Tool & $\bullet$ Eclipse ADT \\
\cline { 2 - 3 } & Development Language & $\bullet$ C, HTML5, JSP \& Servlet \\
\hline \multirow{2}{*}{ H/W } & AVR Controller & Atmega128 \\
\cline { 2 - 3 } & Alarm & LED, Vibrator, Alarm \\
\hline
\end{tabular}

\subsection{Overview of System Design and Development}

Currently, when track workers are engaged in maintenance jobs for tracks or signal control equipment on trackside, a method is used in which a train over-watcher ahead delivers train approaching information to the track workers with hand signs or by means of radios. In this existing method, we cannot exclude the possibility of delivery errors occurring due to weather conditions, work structures, or obstacles, and workers are highly likely to be unable to recognize approaching vehicles as they are absorbed in their jobs. This paper tries to come up with a safety management system for track workers using smart phones, which have been widely spread recently, in order to make up the existing method.

The direction of the design and development of the system is as follows.

We should consider safety for both train driving and track workers at the same time in trackside maintenance jobs. Thus, drive trains just do transmit their real time locations necessary for the safety management system or workers, but they neither have to know workers' locations nor need to stop driving.

Thus, the train application is designed to transmit real time location information of trains to the server, and the worker application to contain functions including transmission of workers' location information, monitoring of driven trains'location information, and Bluetooth connection for communication with the AVR controller. The AVR controller is designed to send signals to vibrators, LED, and alarms in workers' safety jackets when a train is approaching within a safe distance.

This system consists of a server that allows workers to monitor train approaching information by collecting location information from train and track worker applications and transmitting train location information to workers, and hardware modules that can notify workers of train approaching information using the worker application and wireless communication. Figures 1 and 2 present the assembly of the system. 


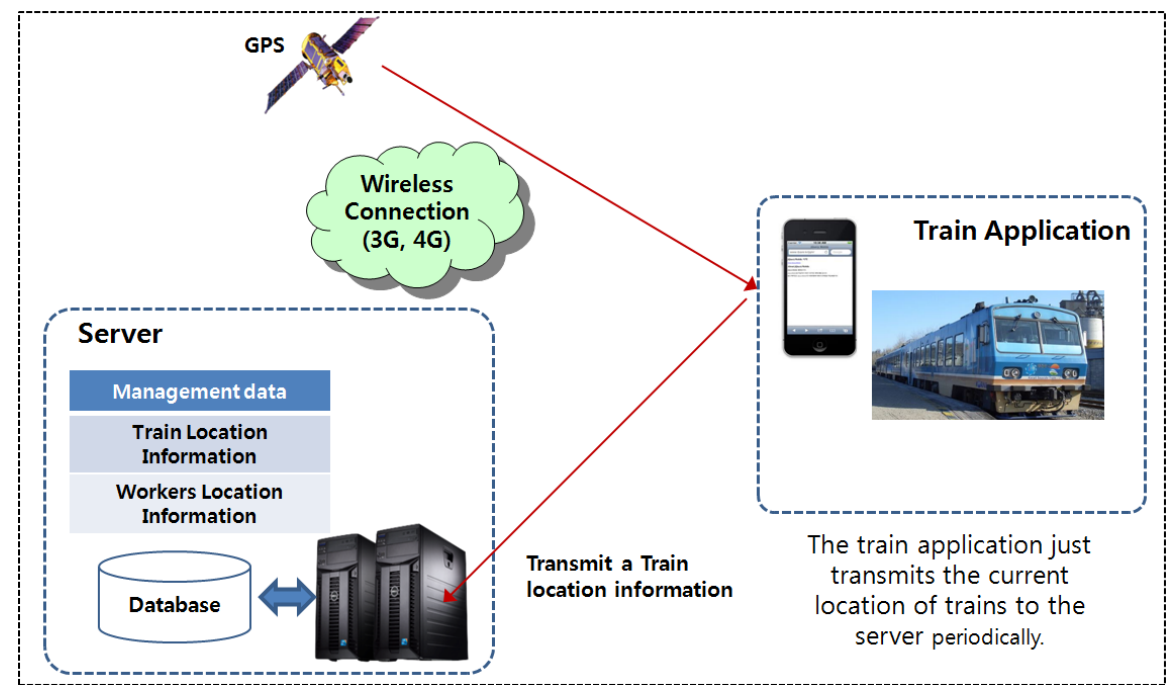

Figure 1. Processing of Train Location Information

Figure 1 shows us the composition of functions of collecting and processing train and track worker location information. The smart phone applications for trains and track workers collect the current location information via the installed GPS, and then transmit it to the server periodically. The train application just transmits the current location of relevant trains to the server. The smart phone application for track workers should transmit workers location information to the server, and also request the server to provide train location information necessary for the embodiment of the safety management system. This is for monitoring train approaching information with workers' smart phones and notifying them of train approaching information through their safety jackets in case of danger.

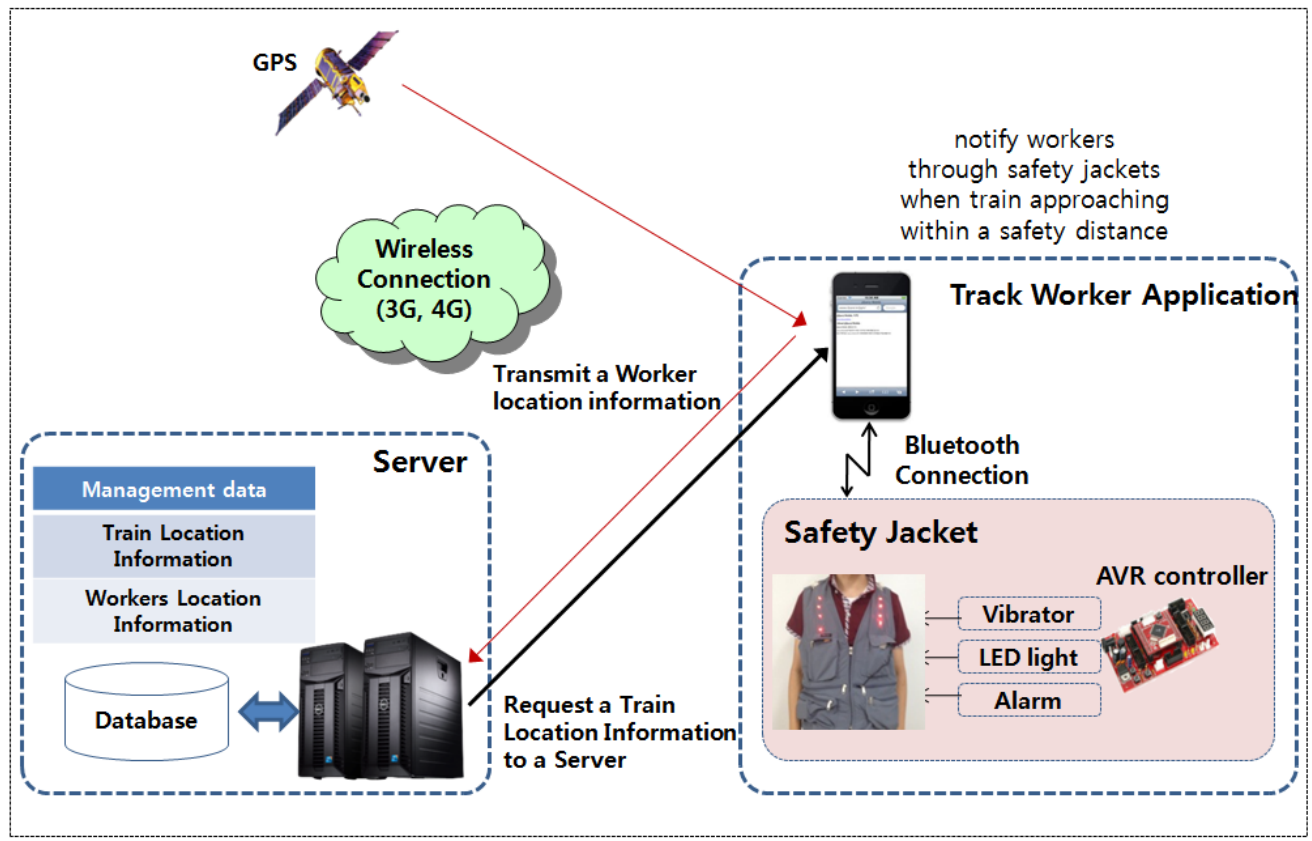

Figure 2. Structure of Safety Management Systems for Track Workers 
Figure 2 represents the worker safety management system consisting of the track worker application and communication modules using Bluetooth. The worker application is designed to monitor real time train locations by receiving train location information from the server, and to notify workers of train approaching through LED, alarms, and vibrators installed in their safety jackets in case of train approaching within a safety distance, which has been established on the basis of the current worker locations.

\section{Study Results}

\subsection{Transmission and Processing of Train and Worker Location Information}

The modules that transmit and process the location information of trains and track workers are the core function of the system. Though it is necessary for using location-based applications like maps, tracking, Facebook, etc., the GPS installed in smart phones is disadvantageous in that its signal is difficult to detect in some closed spaces.

This safety management system is designed to operate for track workers even in tunnels because it transmits their locations with reference to the entrance of a tunnel and uses the $3 \mathrm{G}$ and $4 \mathrm{G}$ mobile networks to request train location information. Also, this system has been designed and developed by reflecting railway personnel and track workers' needs in various situations including trains' approaching rapidity, the establishment of a safe distance, the point of danger notification etc. Figure 3 includes screen shots of the train and track worker applications.

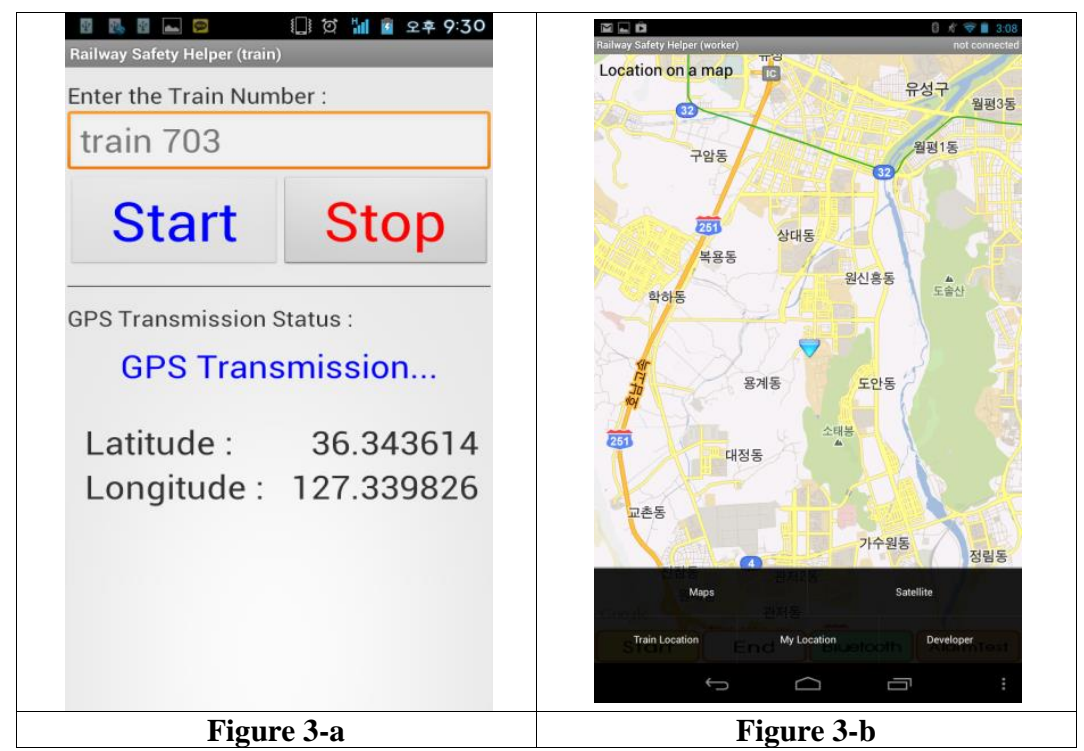

Figure 3. Train and Track Worker Applications

Figure 3-a shows a screen shot of the train application. A train runs the smart phone application to enter its train number and sets it up to start location information transmission. This application is embodied to periodically store longitude and latitude coordinates in the server. Figures 3-b shows screen shots of the worker application. The main menu of the worker application has functions of common and satellite map views and is embodied to identify train and worker locations. It also contains other developer menu functions.

When the menu for train and worker locations is selected, the locations of trains and workers are bold-marked respectively. In the figures, the arrows indicate worker locations 
while the circles refer to train locations. Train locations are still not shown in Figures 3-a, but appear on the map if they approach closer.

The function of train approaching information monitoring is embodied by the worker application receiving the current worker and train locations from the server. Using this function, the application can notify $4 \mathrm{~km}$ train approaching and $2 \mathrm{~km}$ train approaching information, and at the same time it executes danger notification through workers' safety jackets.

The track worker safety management system has been developed to deliver information signals through the safety devices installed in workers' safety jackets. Thus, workers should necessarily search and connect the Bluetooth modules installed in their safety jackets before being engaged in jobs.

Figure 4-a and 4-b, screen shots of Bluetooth button execution, shows a normal connection with the wireless communication device in a safety jacket after searching Bluetooth devices.

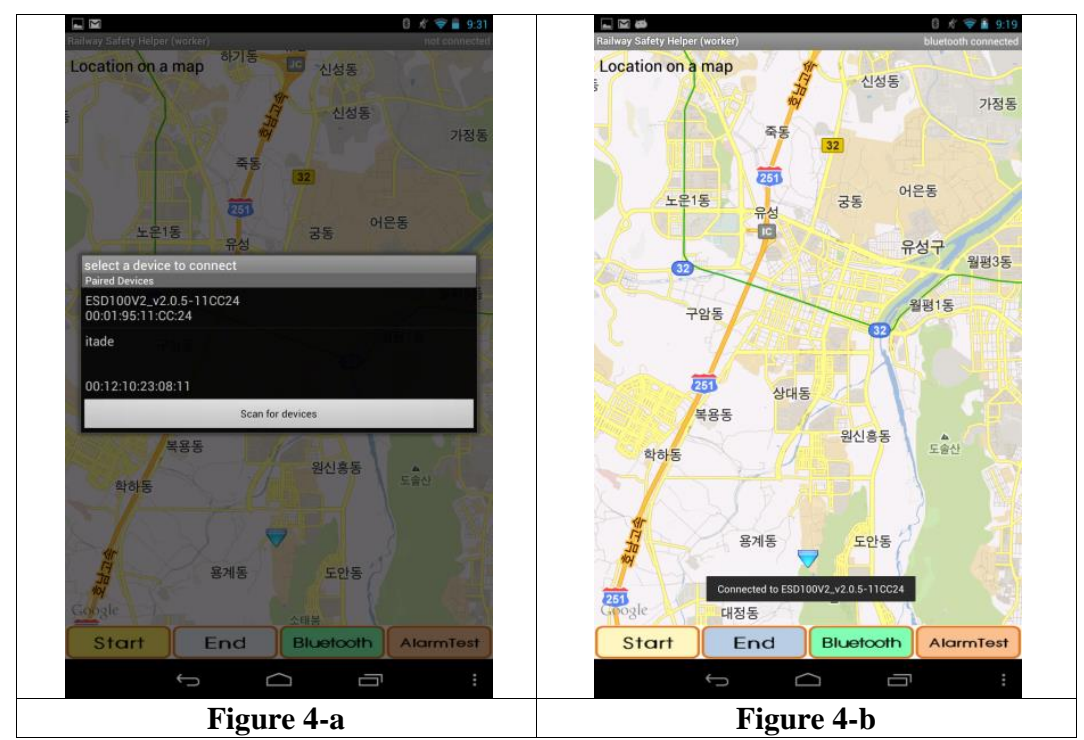

Figure 4. Search and connect the Bluetooth device

\subsection{The Function of Train Approaching Information Monitoring}

The functions of train approaching information monitoring and danger notification for the safety management of track workers are two main functions of the track worker application. However, track workers have difficulty in monitoring train approaching from time to time and are highly likely to be unable to see the danger notification on the screen because they are absorbed in their jobs.

Thus, simultaneously with the danger notification on the screen, another danger notification should be carried out through the LED, alarm, and vibrator installed in a worker's safety jacket, the track worker should run the smart phone application to first push the Bluetooth button for searching and connecting devices, and check by pushing the alarm test button whether his or her safety jacket works normally.

The Bluetooth used in this system is Atmega128 in order to operate the LED, alarm, and vibrator installed in the safety jacket. All the functions in the track worker safety management system can be said to be embodied from the real time location information of trains. 


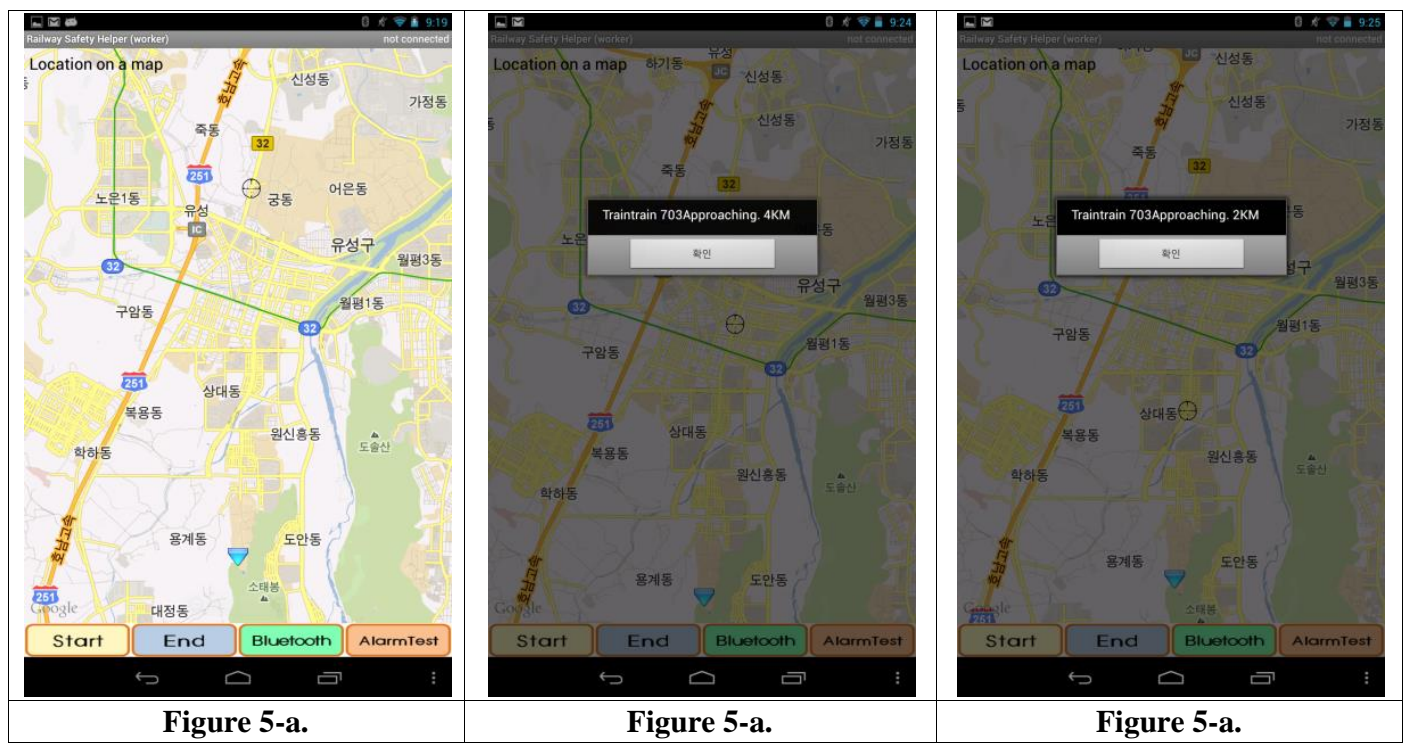

Figure 5. Train Approaching Information Monitoring and Danger Notification

While the train application is in charge of storing real time train locations in the server, track workers should request train locations to the server before job engagement since all the functions of the track worker application are run on the basis of real time train location information. The start and stop buttons starts and stop requesting train locations to the server respectively. Figure 5 shows the danger notification function based on train approaching information monitoring and approaching information.

Figures 5-a, 5-b, and 5-c are screens of monitoring with real time consideration of train approaching information with respect to the current worker locations. In Figure 5-a, it turns out that the locations of workers (arrows) and of trains (circles) are more distant than they should be by the established safety distance (a radius of $4 \mathrm{~km}$ ). Figure 5 -b shows a screen on which workers are notified of the danger of train approaching within $4 \mathrm{~km}$, and simultaneously with this, the workers' smart phone application slowly sounds the primary alarm ten times through the LED, alarm, and vibrator installed in their safety jackets. Figure 5-c shows a screen on which workers are notified of the danger of train approaching within $2 \mathrm{~km}$, and simultaneously with this, the workers' smart phone application slowly sounds the secondary alarm twenty times through the LED, alarm, and vibrator installed in their safety jackets.

\subsection{The Function of Train Approaching Information Notification}

Figure 6 shows the current state of Bluetooth connection, through which danger is notified to workers' safety jackets in various ways. Workers' safety jackets are embodied by using short-range wireless equipment like Atmega128.

There are two methods of notifying workers of train approaching information; one is through the smart phone screen, and the other is simultaneously through the safety jacket worn by track workers. Because workers have difficulty in seeing their smart phone screen or hearing alarms when they are absorbed in their jobs, the signals are directly delivered to their safety jackets through the LED, alarm, and vibrator.

Figure 6-a shows the state of the connection of a Bluetooth device to a worker's smart phone and safety jacket. Also, Figure 6-b shows the state of a safety jacket before danger notification, while Figure 6-c the states of a safety jacket when a train has approached within $4 \mathrm{~km}$ and within $2 \mathrm{~km}$. We can identify an LED light though there are no vibrations and sounds. 


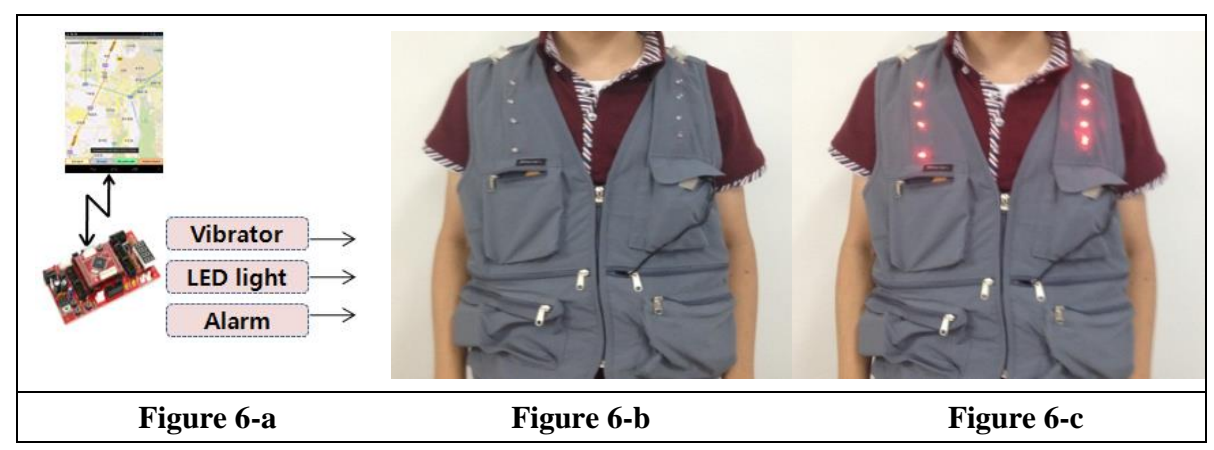

Figure 6. Risk Notification Through Safety Jackets of Worker

\subsection{Results of the Experiments}

In order to reduce the risk of railway traffic accidents of death and injury for track workers, this paper has developed a system that notifies track workers of train approaching information by combining the GPS location providing function of the smart phone and a notification system.

Simulations were performed under conditions similar to actual situations in order to apply the developed safety management system for track workers using the smart phone GPS to trains. First of all, three areas were selected for the simulation in consideration of areas with an insufficient number of base stations and partially closed spaces like tunnels because smart phone use should be enabled in various places due to track workers' job conditions.

Also, for the three sample areas, experiments were carried out about the states of the connection between workers' application and the server, of Bluetooth connection, of data transmission-reception, and of the danger notification motion of the safety jacket..

Table 3. Results of System Simulation

\begin{tabular}{c|c|c|c|c|c}
\hline \multirow{2}{*}{ System Check } & \multicolumn{2}{|c|}{ Module } & \multicolumn{3}{c}{ Simulation Area } \\
\cline { 2 - 6 } & Trains & Workers & A & B & C \\
\hline \hline Server Connection Status & $\circ$ & $\circ$ & $\circ$ & 0 & 0 \\
\hline Buletooth Connection Status & -- & $\circ$ & $\circ$ & 0 & 0 \\
\hline $\begin{array}{c}\text { Data Transmission and Reception } \\
\text { Status }\end{array}$ & $\circ$ & $\circ$ & $\circ$ & $\circ$ & 0 \\
\hline $\begin{array}{c}\text { Safety Jackets Risk Notification } \\
\text { Status }\end{array}$ & $\circ$ & $\circ$ & $\circ$ & $\circ$ & $\circ$ \\
\hline
\end{tabular}

A simulation of trains approaching track workers at speeds similar to actual speeds in order to apply the developed system to trains. As jobs on KTX tracks need not be considered currently, this paper takes the Saemaul train's speed rate of $90 \sim 145 \mathrm{~km} / \mathrm{h}$ as the reference, and the experiments were performed in the three selected areas by means of automobiles instead of trains.

With the start button pushed, the train application begins to transmit GPS data to the server. Also, the worker application connects the Bluetooth module in the safety jacket with the Bluetooth button pushed, and requests GPS data from the server with the start button pushed.

The experiments were performed about the states of server connection, of GPS data transmission-reception in the $\mathrm{DB}$, and of the Bluetooth connection between the worker application and the safety jacket, and the success and failure in the preliminary notification 
motion with trains approaching within a radius of $4 \mathrm{~km}$ and in the main notification motion with trains approaching within a radius of $2 \mathrm{~km}$.

The results of the simulations are as in Table 3. Some problems with the GPS data transmission-reception and the safety jacket motion occurred in early stages of the experiments. However, as they were due to program errors and other factors, all the problems were eliminated in the course of repetitive experiments.

As a result of the simulations, very satisfactory outcomes were shown in every item. Though there possibly were differences in experimental condition, given that the speed rate of an approaching car is $80 \mathrm{~km} \sim 100 \mathrm{~km} / \mathrm{h}$ while that of an approaching train is $90 \mathrm{~km} \sim 145 \mathrm{~km} / \mathrm{h}$, we judged that such differences in approaching speed rates could be ignored as the stability of GPS data transmission-reception was guaranteed.

\section{Conclusion}

In order to secure the safety for track workers who are engaged in trackside jobs, this paper has developed a safety management system for track workers using GPS information provided by smart phones. The developed system does not need the construction of an independent wireless communication system, and is designed to notify track workers of train approaching information by using a simple Bluetooth module and safety jackets. Also, it is advantageous in that it helps to build a wireless communication system at a low price by using private smart phones and an application. When it is applied to track workers, the system is expected to contribute itself to the improvement of track workers' job environments and work efficiency as well as railway accident avoidance and safety promotion.

\section{Acknowledgements}

The authors would like to thank Y. Nam, H. Kim, H. Joo, M. Lee of Mokwon University, Daejeon, Korea, for their support. This work was supported by the Schematic Design Study funded by ETRI (Electronics Telecommunications Research Institute), Korea (no. EA20124751).

\section{References}

[1] Seoul Metro, Handling Accident of Death and injury in Subway, (2004).

[2] Ministry Of Construction \& Transportation, Guidelines on the Reports of Railway Accidents 2007-512, (2007).

[3] Statistics Korea, Railway Accident Statistics, (2012).

[4] C. W. Park, J. B. Wang and Y. O. Cho, "Development of Accident Scenario Models for the Risk Assessment of Railway Casualty Accidents", Journal of the Korea Society of Safety, vol. 24, no. 3, (2009), pp. 79-87.

[5] S. L. Kwak, S. H. Hong, C. W. Park and Y. K. Bhang, "Safety Measures for the Track Work Safety", Proceedings of the Korea Society for Railway, (2004), pp. 53-58.

[6] J. K. Hwang, H. J. Jo, Y. K. Yoon, Y. K. Kim, Y. J. Jang and Y. H. Ko, "Development of safety Equipment for Protection of trackside personnel maintaining using radio frequency equipment", Journal of the Korean Society for Railway, vol. 12, no. 5, (2009), pp. 738-743.

[7] Korea Railroad Research Institute, "Positioning system with RFID and method of preventing train accident by using thereof", Korea, (2010) October.

[8] Y. J. Lee, M. S. Kim, J. S. Chae, W. S. Yoo and J. W. Lee, "An Intelligent Control Scheme of Moving Objects based on Smartphones", Journal of the Korean Institute of Information Scientists and Engineers, vol. 28, no. 2, (2012), pp. 5-7. 


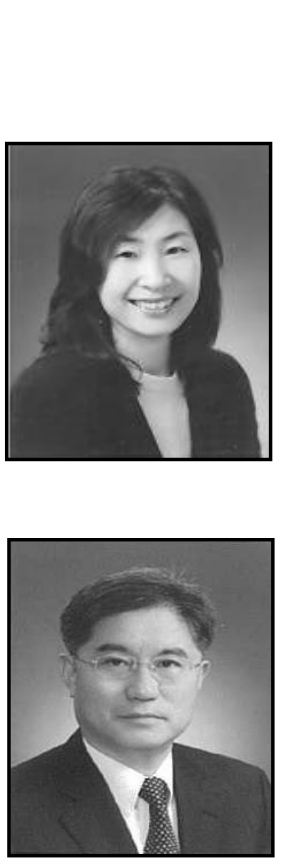

\section{Authors}

Jin Hee Ku received the B.S. degrees in computer science from Hanbat University, Korea, in 1994. And She received the M.S. degree and $\mathrm{Ph} . \mathrm{D}$. degree in computer science Education \& Industrial Education from ChungNam University, Korea in 2001 and 2010, respectively. Currently, She is an assistant professor of the Dept of Liberal Education, Mokwon University. Her main research interests include Smart Learning and Context-Aware and Learning Management System.

Duk-Kyu Park received the B.S. degree in electronics from University of Incheon, Korea in 1984, the M.S. degree in electronics from Yonsei University, Korea in 1986, and the Ph.D. degree in electrical engineering from Keio University, Japan in 1992. From 1992 to 1995, he worked as a Special Researcher in Science and Technology at the Communications Research Laboratory(CRL), Ministry of Posts and Telecommunication of Japan. He is now a Professor in the Dept. of Information Communication Eng. at the Mokwon University, Daejeon, Korea. His research interests include spectrum policy, spectrum allocation and Technical Regulation for radio communication system. 
International Journal of Control and Automation Vol.6, No.5 (2013) 